
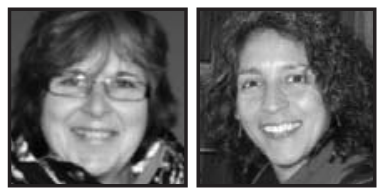

\title{
Balancing Act: Respecting the Required Curriculum While Honouring the Real Curriculum
}

Teri Todd \& Jacquie Medina, California State University, Chico

\section{ABSTRACT (Press Here for Sound)}

Two authors from different disciplines share their views on meeting both the curriculum set forth by the institution and honouring the meaning that students make of their own learning. Believing in the importance of learning that reaches beyond that which is taught, the real curriculum, the authors discuss the challenge of finding a balance between assessing required course content and honouring individual growth in our assessment-laden society.

\section{Introduction}

he importance of moving beyond simple regurgitation of information
by students is increasingly recognized by educators. This article suggests
finding a balance between the curriculum required by the institute and the value of deeper learning, or the real curriculum. The authors present their own stories of how they have come to value the real curriculum and find balance with the required curriculum.

\section{Teri's Story}

As a university instructor I took the business of covering expected content very seriously. I studiously planned lectures and designed activities to encourage students to use, and reflect on, what they had learned. I assessed students on what I 
believed was critical content knowledge. Therefore, it was with some surprise that I listened to students answer a question which I asked on the final day of class. I asked "What did you learn in this class?" As I walked slowly back to my office I reflected on the answers and found that I felt a sense of pride and accomplishment, not because their answers reflected the curriculum outlined in the course syllabus, but because the learning they spoke of was a far deeper learning which enabled them to change their world-view.

My high school and undergraduate education consisted, primarily, of listening, reading, and answering test questions. I spent formidable amounts of time memorizing facts which I kept in useful memory for a short period of time, typically just until the exam was over! As I think back to those years I remember very little of what I learned in the classroom but I do remember an internship, a special hands-on project, and a special bond with a professor. The knowledge I recall from these experiences is a mix of what the book or lecture said and the feelings and outcomes of my experience. This "constructed" knowledge is what led me to my first job, compelled me to attend graduate school, and still guides much of my thinking today.

Employers are searching for graduates that can take knowledge and create new products, students who can look at a problem and find a solution, and people who are able to apply theoretical constructs. Our job as instructors, professors, or teachers is to not only teach theory, but also encourage each student to make meaning of this knowledge internally. Only in this way will students be able to create new knowledge that is of practical value to themselves (Hanson \& Sinclair, 2008). Unfortunately too often students complete courses without assimilating the content. Kaste (2004), a professor in teacher preparation, made this very point when she stated, "it is often the case that the university course leaves little impression on pre-service teachers in either philosophy or practice" (p. 32).

This idea has led me to look at curriculum from two perspectives: required curriculum and real curriculum. I use the term "required curriculum" to refer to the formal content of a course prescribed by the institution while the term "real curriculum" represents the true learning or meaning making by the student. Required curriculum is typically designed by program coordinators and consists of a set of classes designed to form a course of study that will provide the student with critical content knowledge for a particular field of study. With that in mind, where or how does the real curriculum fit? How does one measure true learning? 
This constructivist way of thinking is not new and has been an issue in education in recent years. Educational models which are based on constructivism have been developed and there is a mixture of the traditional didactic methods of knowledge transmission and experiential education in many educational institutions (Richardson, 2003; Sudzina, 1997). Interestingly, and not dependent on which teaching orientation is chosen, courses are typically created with specific student outcome expectations and outcome measurements. These facts are then stated in syllabi, and students seem to appreciate when they are concrete. In addition, we are often evaluated as teachers with regards to how well the course objectives are met. The required curriculum is very apparent while the real curriculum is invisible; tension can occur as instructors work to meet the required curriculum and at the same time honour the real curriculum. Creating a balance between the two becomes necessary.

How do we reconcile these two viewpoints? How do we, or should we, measure deeper understanding? Do the goals of the course remain tied to the outcome measures and we simply hope deeper learning occurs? In the case of my discipline, adapted physical activity, this deeper learning may include the creation of a new understanding of disability and people with disabilities. This learning often occurs during the first-hand experiences provided as part of the learning environment. Theoretical information is transmitted via traditional techniques: readings, lectures, discussion, and films, and it is this information that matches the course content and is tested to establish course outcomes. Field work, designed to promote handson application of the information imparted during the course, is carefully constructed to lead the student to a level of independent functioning. There are aspects of handson learning that can be evaluated, and often are, but they may not reflect changes in attitude or ways of thinking. Therefore it may be impossible to evaluate if students have attained any of the real curriculum.

The idea of constructivist pedagogy dates back to the early 1900s when Dewey (1933) suggested that knowledge is created through learning as a process of construction and reconstruction of meaning as the learner engages in active, systematic, informed experiences. Piaget (1971) proclaimed a similar view of learning; he explained that knowledge is the process that is created by the activity of the learner in interaction with the environment. With development and experience, a child's levels of reasoning change and the child begins to engage in complex reasoning. The term constructivism was formally adopted in the mid-1960s and is influenced greatly by Piaget and Vygotsky (Watson, 2000). Though institutes of higher education have expressed interest in constructivist education models, there is limited empirical evidence of effective teaching practices (Richardson, 2003). Traditionally, education 
has been conservative and relies on high-stake testing procedures which not only allow student promotion, for instance adequate GRE scores are critical for admission to many graduate programs, but also indicate the effectiveness of the institution. This conservative nature of education was observed when Hanson and Sinclair (2008) interviewed 277 professors in 92 faculties about the importance of three student learning outcomes: theoretical knowledge, professional skills, and knowledge creation. The majority of university lecturers perceived the most important learning outcome of undergraduate education was theoretical knowledge. Even more troubling is that although teacher education programs have improved in discussing many issues, for instance diversity, little is done to model active learning practices in the university classroom (Kaste, 2004). Therefore, even though teachers may prescribe to a constructivist model, they probably will not have experienced the method in the classroom.

As an adapted physical activity instructor, I believe it is essential that my students have first-hand experience. As in many aspects of dealing with people, all the answers are not in the book. Students must create a knowledge base from which they can meet the vast demands of their job. They must be able to analyze situations, make decisions that are practical, effective, and ethical, and be able to evaluate the outcome. These skills are taught directly, are required, and can be observed and measured. Of equal importance is the student's ability to maintain composure in a difficult situation, to display energy and happiness in order to motivate students, and to act compassionately and respectfully to all people. This list of skills is not as easy to teach. These are the skills that I believe come from the true learning and reflect the real curriculum. This does not reflect the knowledge typically evaluated by written or oral test questions, nor is it the focus of videotape analysis. Yet, these skills/attitudes enable a teacher to be great at the job.

As an instructor using practical experience as part of course content I have to balance the two curricula.I must be ready to help students construct knowledge, to help them use their experiences to create new meaning. This may require me to follow a student's lead, to alter my agenda for a lesson, and take opportunities to connect experience to theoretical notions. In turn, though these opportunities are wonderful moments to create knowledge, I run the risk of not covering the curriculum that was set out for the lesson. If this occurs in lesson after lesson, tension can mount, especially if outcome measures are predetermined. The question that arises is: If a teacher values the development of knowledge from experience and believes that is the true learning, does this become the priority? 
There is some evidence to suggest that hands-on learning does in fact lead to changes in attitude and the way one thinks about topics. In fact, Mentokowski and Associates define learning that lasts, or deep learning, as "it connotes change in behaviour and flexibility in perspective" (2000, p. xv). Sudzina (1997) reported that students who had to use theoretical information to solve problems presented in case studies made gains in moral reasoning when evaluated by a standardized test. Kaste (2004) found that her students expanded their notions about teaching, learning, and diversity through interaction with diverse learners. As teachers we can guide students and hope that the meaning they make of the knowledge they acquire is beneficial to their development as a person, their career, and society. Even though the importance of meeting the required curriculum often is considered of more value than the real curriculum in many of today's classes, it is the true learning, the real curriculum, which drives people to fulfillment. When a student articulates the shift in his or her paradigm, I know that true learning has taken place and a foundation of knowledge is being formed. I interpret this as success.

\section{Jacquie's Story}

I have always been a fan of structure and clear expectations. Tell me what I need to do and know and I will make it happen. I succeeded in the traditional school setting by reciting rules of grammar, verses of long-forgotten poems, and names and dates significant in history. Rote memorization served me well to attain the letter grade of choice on the short-term test, but long-term memory and application of knowledge was gone like the wind as I became introduced to new material and information. I finished my early studies with the understanding that knowledge acquisition and well- defined goals would propel me through life. I had so much to learn.

One day, in my first job out of college, I found myself in the forest, on the top of a 25-foot wooden rappel tower, with a 10-year-old girl crying in fear of descending the tower. She was properly wearing the required safety gear, understood the climbing systems, and had swiftly climbed the pole to ascend the tower. She was safe. But now she stood before me crippled by her fears, frozen in position, unable to listen or communicate rationally. What was I to do? I searched my brain for ideas and reflected upon experience with lightning speed. The issue was not about gear, technique, information, or achievement. The issue was much bigger. It was about the human spirit and how the experience was impacting the individual and how the individual was going to deal with it, learn from it, and make application. The girl was fine. With the 
support of others and efforts to address her fears, she came down the tower. But I had changed. It was my own growth and understanding as a teacher that blossomed.

I have come to believe that the real curriculum is the development of the whole person that evolves through the learning experience-not just the content presented nor the student's ability to articulate his or her knowledge and understanding of the content through assessments, but the personal growth and construction of knowledge that occurs. What does the student bring to the experience, and what does the student interpret the value to be? How is the student affected by the material, discussions, challenges, and interaction with others? What perspectives and ideas do they glean and develop on their own? What does the student take from the experience and what does he or she do with this information, his or her new ideas and emotions? These are the questions that need to guide us and to be asked: how is the student transformed or not from the experience?

As teachers we are charged with the responsibility to teach the required curriculum and achieve desired learning outcomes. How we foster both the required curriculum and real curriculum can be challenging. We give a child a jar of Play-Doh and teach him or her how to mould a dog. What if the child understands the material, its malleability and uses, but sees a pancake, a house, or a cat, not a dog? The student learns that if the Play-Doh is left out in the air too long it gets hard, and that getting back to the original color is quite difficult, if not impossible, once colors have been mixed. Has the child met the learning outcomes? It seems to depend on whether I am measuring learning on the required curriculum or real curriculum. Perhaps it is both, and that is our challenge: to find balance and value in both.

To do so, it is critical to create an experience that fosters the intended outcomes and promotes personal growth, construction of knowledge and understanding of and beyond the content. For this to happen, we must move away from the real curriculum being the "hidden curriculum" to the real curriculum being the "understood curriculum." We must be clear on what the real curriculum is, articulate it, and move forward in fostering desired outcomes.

In the field of outdoor education, our classroom is the natural environment. The risks are real and the consequences immediate. The fresh air, sounds of nature, and interaction with plants, animals, and humans in a less stimulated and technologically driven world slows the students' pace and opens their minds and hearts to new ways of doing and thinking. While the benefits of the natural environment are immeasurable, a traditional classroom can also become a place where students can 
open their minds and hearts to new ways of doing and thinking if we shift our focus from imparting knowledge and skills to fostering a learning experience. How do we do this? Trust.

Trust in oneself to create an opportunity for learning to occur and letting the learning experience unfold.

Trust in your students to be accountable, construct knowledge, and make application without over processing and assessing the experience to the point that the students' own meaning making and value dissolves.

Trust in the process - that education occurs through reflection and that this reflection may or may not result in desired or required outcomes immediately if at all, but that what the student gleans has value and application.

Models of experiential learning emphasize the role of experience and reflection in the learning process (Kolb, 1984; Jarvis, 1987a, 1987b; Joplin, 1995). Kolb's model is cyclical in nature and consists of four elements of learning: (a) concrete experience, (b) reflective observation, (c) abstract conceptualization, and (d) active experimentation. A student has an experience and the experience is followed by reflection. From this reflection, the student gains new insights and understanding which can lead to creating new ideas and concepts as the student actively experiments creating new experiences from which the cycle can begin again. Jarvis (1987a) expanded on the work of Kolb, but thought Kolb's model was neat and oversimplified.

According to Jarvis (1987a), learning is the process of transforming experience into knowledge, skills, and attitudes, and that while learning may begin with experience, experience does not necessarily equate to learning. Jarvis (1987b) believed that "some experiences may not result in learning" (p. 165), that students may be led elsewhere from the experience. In Jarvis' (1987a) model of the learning process, a potential experience can result in nine different paths that may or may not lead to learning. Potential outcomes presented include a person "may grow and develop as a result of the learning experience, may remain virtually unaltered, or may actually be harmed as a result of the experience of learning" (Jarvis, 1987a, p. 24).

So what is our role as teacher? Create experiences that offer the student immersion in the course material. We understand the material and required curriculum; how can it be delivered in an experience that will also foster the real curriculum? Allow for reflection of the experience both individually and guided so that students can glean ideas and concepts that mean something to them. In Priest and Gass's 
(1997) generations of facilitation, "letting the experience speak for itself" allows students to have the experience and let it be theirs and what they make of it without breaking it apart using processing techniques or assessment tools. "Debriefing the experience" involves learning through reflection, and often occurs after an experience. Journal writing is a reflective tool that promotes individual reflection. This reflection can be guided by the student and/or teacher. Small and large group discussions and activities can also be used to debrief the individual and group experience. Framing the experience and directly and indirectly front-loading the experience are more developed methods of facilitation that can be used during the experience and before and afterward to facilitate the experience. All of these strategies provide opportunities to affirm required curriculum and promote the real curriculum. However, Wattchow (2008) argues that Priest and Gass's generations of facilitation overlook the value of the less sophisticated technique of "letting the experience speak for itself."

Joplin (1995) differentiates between experiential learning as when the "debrief may occur within the individual" (p. 19) and experiential education as when the student's learning is made public. Joplin states, "It is the publicly verifiable articulation which makes experience and experiential learning capable of inclusion and acceptance by the educational institutions" (p. 19). Wattchow (2008) finds Joplin's pedagogy problematic in its relationship between the experience within the learner and the "necessity for articulation and public verification of that experience" (p. 66). Wattchow argues that while this approach may move the learner more deeply into his/her own verbalized experience, the approach "may not move the individual more deeply into his/her experience of the world" (p. 66). Perhaps the technique of "letting the experience speak for itself" can provide opportunity for student meaning making that teacher guided facilitation approaches cannot provide. By giving students the necessary time and venue for introspection, we can minimize the potential outcomes of diminishing the experience, its value, and potential for learning.

Lastly, continue the cycle. Encourage new perspectives and ideas and provide additional experiences to apply new knowledge, to develop the real curriculum, and to introduce more of the required curriculum. As Einstein so eloquently stated, "I never teach my pupils, I only attempt to provide the conditions in which they can learn best" (Priest, Gass, \& Gillis, 2000, p. 6). The process of balancing and finding value in the required and real curriculum involves shifting paradigms. Namely, making the shift away from the view of "educating students" to "providing learning experiences," and fostering opportunities for students to learn (acquire skills and knowledge) rather than educating or imparting skills and knowledge on students. It may be 
argued that these concepts are one in the same, however, this paper proposes that beyond semantics, educating and fostering learning experiences are very different philosophies and can result in different strategies and outcomes for student learning.

\section{Making Meaning of the Real Curriculum}

What does all of this mean and why does it matter? It matters because the real curriculum is the fabric in which the required curriculum is woven. We must find a way to balance the value and growth of both curriculums in our students and institutions. In an assessment-laden society, we must also tackle the challenge of measuring the real curriculum. This proves challenging for a variety of reasons. How do we assess something that is dynamic and unique to the individual learner? Outcome measures for university classes are typically concrete, as are the evaluation methods. This is required by the schools and expected by the students. This elicits questions such as: What types of assessment will capture the learning I want to foster? (Windschitl, 2002). How can I gain the support of administrators if I change assessment methods? And finally, is it ethical to evaluate students on the meanings that came from their experience? If we assess the real curriculum-shifting paradigms, changes in attitudes and world-views, feelings, compassion, respect-how can we determine what students are actually learning if we are assessing it through our own lenses as teachers and administrators?

We are left with the challenge of finding practical means of assessing student meaning making that not only represents the value of student learning and the real curriculum, but also meets institutional assessment requirements. Can we simply honor a student's efforts at making meaning from an experience? Perhaps a demonstration or articulation of learning grounded in the material but applied and disseminated along the learner's path would be viable. Are we in a position to judge if the student made the correct meaning? Within this lies the tension when evaluating student learning, Windschitl (2002) states that "it is equally important to honour student's efforts at meaning-making, even when it reflects immature understanding. As teachers try to strike a balance between their obligations to the discipline and their obligation to the learner, they must frequently settle for partial understandings on the part of learners" (p. 149). We argue that a student's partial understanding of the required curriculum coupled with application and understanding to self and the world is preferable to the ability to demonstrate complete content knowledge with little to no meaning to the learner. 


\section{References}

Dewey, J. (1933). How we think. A restatement of the relation of reflective thinking to the educative process (Rev. ed.). Boston: D.C. Health.

Hanson, J., \& Sinclair, K. (2008). Social constructivist teaching methods in Australian universities - reported uptake and perceived learning effects: a survey of lecturers. Higher Education Research \& Development, 27, 169-186.

Jarvis, P. (1987a). Adult learning in the social context. New York: Croom Helm.

Jarvis, P. (1987b). Meaningful and meaningless experience: Towards an analysis of learning from life. Adult Education Quarterly, 37, 164-172.

Joplin, L. (1995). On defining experiential education. In K. Warren, M. Sakofs, \& J. Hunt (Eds.), The theory of experiential education (pp. 15-22). Dubuque, IA: Kendall/Hunt.

Kaste, J. (2004). Scaffolding through cases: diverse constructivist teaching in literacy methods course. Teaching and Teacher Education, 20, 31-45.

Kolb, D. A. (1984). Experiential learning: Experience as the source of learning and development. Englewood Cliffs, NJ: PrenticeHall.

Mentokowski, M., \& Associates (2004). Learning that lasts: integrating learning, development, and performance in college and beyond. San Francisco: Jossey-Bass.
Piaget, J. (1971). Biology and knowledge: An essay on the relations between organic regulations and cognitive processes. Chicago: The University of Chicago Press.

Priest, S., \& Gass, M.A. (1997). Effective leadership in adventure programming. Champaign, IL: Human Kinetics.

Priest, S., Gass, M., \& Gillis, L. (2000). Essential elements of facilitation. TARRAK Technologies.

Richardson, V. (2003). Constructivist pedagogy. Teachers College Record, 105, 1623-1640.

Sudzina, M. (1997). Case study as constructivist pedagogy for teaching educational psychology. Educational Psychology Review, 9, 199-218.

Watson, J. (2000). Constructive instruction and learning difficulties. Support for Learning, 15, 134-140.

Wattchow, B. (2008). Speech, silence, and the embodied experience of place. In K. Warren, D. Mitten, \& T.A. Loeffler (Eds.), The theory and practice of experiential education. Boulder, CO: Association for Experiential Education.

Windschitl, M. (2002). Framing constructivism in practice as the negotiation of dilemmas: An analysis of the conceptual, pedagogical, cultural, and political challenges facing teachers. Review of Educational Research, 72, 131-175. 


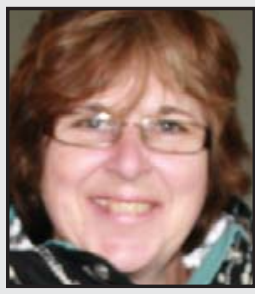

Teri Todd, Ph.D. is an Assistant Professor in the Department of Kinesiology at California State University, Chico, in the discipline of Adapted Physical Activity. She has worked in the disability area for over 25 years and is an advocate for people with disabilities. Her research interests include empowering people with autism and cognitive disabilities through personcentered planning and self-determination. She completed her doctoral degree in Educational Psychology at McGill University.

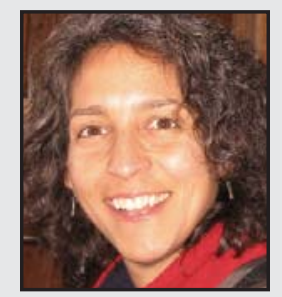

Jacquie Medina, Ed.D., is an Assistant Professor in the outdoor education program at California State University, Chico. Her experience in the field spans over 20 years and includes administering outdoor adventure programs and teaching theory and field-based courses in outdoor education and recreation. She is passionate about teaching, learning, the natural environment, and creating experiential methods for sharing knowledge. Jacquie completed her doctorate in Educational Leadership at the University of Northern Colorado. 